Journal of Finance and Banking Review

Journal homepage: www.gatrenterprise.com/GATRJournals/index.html

J. Bank. Fin. Review 2 (3) 1 - 7 (2017)

\title{
Single Beta and Dual Beta Models: A Testing of CAPM on Condition of Market Overreactions
}

\author{
Ferikawita M. Sembiring ${ }^{1 *}$, Sulaeman Rahman ${ }^{2}$, Nury Effendi ${ }^{3}$ and Rachmat Sudarsono ${ }^{4}$ \\ ${ }^{1}$ Jenderal Achmad Yani University, Bandung Indonesia. \\ 2,3,4 Padjadjaran University, Bandung Indonesia.
}

\begin{abstract}
Objective - A previous study conducted by the same authors found that the conditions of market overreaction occurred in Indonesia and the market factor in CAPM, or a single beta, is able to explain the portfolio returns. As a continuation of that study, we now use the concept of conditional CAPM, or a dual beta, to test whether the performance of the dual beta can outperform the single beta.

Methodology/Technique - The research uses the stocks of non-financial sector company on the Indonesian Stock Exchange during the period between July 2005 and December 2015, which have been divided into two portfolios; the winner and the loser. The conditional CAPM is applied by separating the market into upstream markets and downstream markets, so the dual beta model can be formulated.

Findings - The results are consistent with the findings of Pettengill et al. (1995). The results of a single beta test do not comply with the conditions required in the CAPM model and this can be corrected through conditional beta testing that includes the testing on the up beta, down beta, and the dual beta.

Novelty - The dual beta model can explain the returns of the portfolio in accordance with the expected results in CAPM testing. The explanation by using the dual beta model is more accurate and more successful than the single beta model.

Type of Paper: Empirical.
\end{abstract}

Keywords: Conditional CAPM, Dual Beta, Loser Portfolio, Winner Portfolio.

JEL Classification: J11, G31.

\section{Introduction}

The Capital Asset Pricing Model (CAPM) is an estimation model of returns that states which market factors are the determinants of stock returns or portfolios in an equilibrium market. In this market condition, the investors are not able to earn abnormal returns, however empirical studies have resulted in opposite findings. This might be caused by anomalies in the market in which the investors can apply an active investment strategy to obtain abnormal returns. One such strategy is a contrarian investment strategy that can be applied in conditions of market overreactions.

\footnotetext{
* Paper Info: Received: January 13, 2017

Accepted: June 21, 2017

* Corresponding author:

E-mail: ferikawita@yahoo.com

Affiliation: Jenderal Achmad Yani University, Indonesia.
} 
Many studies have been conducted to determine whether the market factor in the CAPM can explain the returns on a portfolio formed in market overreaction conditions. The previous study by the same authors found that overreaction conditions occurred on the Indonesian stock market during the period between 2005 and 2015 with indications of a return reversal on stocks. In this situation, the stocks winners turn into losers and the losers stocks turn into winners. The results also prove that, by applying a contrarian investment strategy, market factors in the CAPM model have a positive affect while the beta of winners is greater than losers but produces a lower return (Sembiring, et al., 2016). As a continuation of that study, and also as the aim of the current study, we will test conditional CAPM in order to determine whether the model can explain the returns of winners and losers more effectively.

Pettengill, et al., (1995) estimates that beta operates separately in different conditions of risk. Specifically, it is posited that the value of risk premium is significantly different from zero (positive in a high market, and negative in low market). When CAPM is tested separately in these conditions, the relationship between beta and portfolio returns become more powerful and significant. The methodology, hereinafter known as the dual beta model, is supported by Fletcher (2000) for the scope of international stock markets, and Charteris (2014) for the South African stock market.

Many studies using a dual beta model have been conducted but only a few of those studies have tested portfolios of market winners and losers that have been formed in market overreaction conditions. Therefore, this study will empirically test whether a dual beta model can outperform a single beta model in explaining the portfolio returns of markt winners and losers.

Sharpe (1964), Lintner (1965), and Mossin (1969) were the first researchers to propose the Capital Asset Pricing Model (CAPM). The test intends to prove that: (a) the relationship between risk and returns is linear and positive, (b) The intercept is equal to the level of risk-free assets (zero), and (c) The only measurement of relevant risk is beta. However, Lintner (1965) found that the intercept in the CAPM model is greater than the monthly returns of US Treasury Bills as a level of risk-free assets.

Black, et al. (1972) conducted a cross-sectional regression between the average excess returns of the portfolio and the estimated beta. The results of that study indicate that a portfolio with low beta has a positive alpha, while a portfolio with high beta has a negative alpha. This proves that intercept is not equal to zero. Furthermore, Fama and Macbeth (1973) propose several methodologies to test the CAPM model and study the hypothesized existence of a positive relationship between the beta and average expected returns. Their findings show that: (a) non-beta factors, or idiosyncratic risk, is different from zero but not significant, (b) there is a linear relationship between risk and returns, (c) there is a significant positive relationship between risk and returns, and (d) the alpha value as a intercept is not equal to zero but is positive and significant. In his study, Reinganum (1981) then attempted to select stocks based on beta. The findings of that test show that a portfolio with a high beta does not have a higher return than a portfolio with a low beta.

Conditional CAPM in the form of conditional beta or a dual beta was first introduced by Fabozzi and Francis (1977) when testing beta instability based on the condition of the business cycle of bullish and bearish markets. Bhardwaj and Brook (1993) also used a dual model of beta to test the effect of size on beta in bullish and bearish markets. They found that the behaviour of beta is significant in both types of markets which are classified when the market returns are greater (smaller) than the median return.

The conditional beta assumption is on the differences in market conditions and market timings. The market will be segmented into an up market and a down market. The down market will generate a down beta that depicts lower systematic risk, so that investors' required rate of return will be lower as a result of the low level of risk assumed. In contrary, an up market will generate an up beta reflective of the high systematic risk assumed. The investors' required rate of return will therefore be higher.

For the development of research related to testing the validity of CAPM, Pettengill, et al. (1995) uses the methodology of the conditional relationship between beta and returns, known as conditional CAPM. Pettengill, et al. (1995) found a significant and systematic relationship between risk and returns in both the up market and the down market. When the excess return of the market is positive, the CAPM predicts a positive relationship 
between beta and returns. However, when the excess return of the market is negative, the CAPM model predicts a negative relationship.

Based on the above description, the hypotheses of the study are as follows:

$\mathrm{H}_{1}$ : Slope SML portfolio winners in an up market is positive.

$\mathrm{H}_{2}$ : Slope SML portfolio winners in a down market is negative.

$\mathrm{H}_{3}$ : Slope SML portfolio losers in an up market is positive.

$\mathrm{H}_{4}$ : Slope SML portfolio losers in a down market is negative.

$\mathrm{H}_{5}$ : Dual beta has a positive effect on the return of winner portfolios.

$\mathrm{H}_{6}$ : Dual beta has a positive effect on the return of loser portfolios.

\section{Methods}

The respondents in this research are all active non-financial stocks on the Indonesian Stock Exchange (BEI) for the period between July 2005 and December 2015. These stocks have been classified into portfolios of winners and losers based on the reversal of returns that occurs in market overreaction conditions. There are 20 portfolios for winners and 20 portfolios for losers.

The stages of data analysis design are as follows:

1) Operate time series regression based CAPM to estimate the single beta.

$$
\left(R_{p}-R_{f}\right)=\alpha_{p}+\beta_{p}\left(R_{m}-R_{f}\right)+e_{i}
$$

2) Operate time series regression based CAPM to estimate the dual beta.

$$
\begin{aligned}
& \hat{\mathrm{R}}_{\mathrm{it}}=\gamma_{0}+\beta_{\text {upi }} \hat{\mathrm{R}}_{\mathrm{mt}} \delta+\beta_{\mathrm{dwi}} \hat{\mathrm{R}}_{\mathrm{mt}}(1-\delta)+\mathrm{e}_{\mathrm{i}} \\
& \delta=1 \text { is an up market condition, where }\left(\mathrm{R}_{\mathrm{m}}-\mathrm{R}_{\mathrm{f}}\right)>0 \\
& \delta=0 \text { is a down market condition, where }\left(\mathrm{R}_{\mathrm{m}}-\mathrm{R}_{\mathrm{f}}\right)<0 \\
& \mathrm{E}(\mathrm{Y} \mid \delta=1) ; \hat{R}_{i t}=\gamma_{0}+\beta_{u p i} \hat{R}_{m t}+e_{i} \\
& \mathrm{E}(\mathrm{Y} \mid \delta=0) ; \hat{R}_{i t}=\gamma_{0}+\beta_{d w i} \hat{R}_{m t}+e_{i}
\end{aligned}
$$

3) Operate cross section regression to estimate the single beta and the dual beta.

$$
\begin{aligned}
& \hat{R}_{i}=\gamma_{0}+\lambda_{1} \beta_{u p i} \delta+\lambda_{2} \beta_{d w i}(1-\delta)+e_{i} \\
& \mathrm{E}(\mathrm{Y} \mid \delta=1) ; \hat{R}_{i}=\gamma_{0}+\lambda_{1} \beta_{u p i} \hat{R}_{m t}+e_{i} \\
& \mathrm{E}(\mathrm{Y} \mid \delta=0) ;
\end{aligned}
$$

4) Estimate the relationship between the dual beta and the portfolio returns.

$$
\overline{R_{i}}=\alpha_{0}+\alpha_{1 .} \beta_{1 i}+\overline{e_{i}}
$$

5) The operating procedure of the t-test and f-test uses the EViews program for testing the proposed hypothesis.

\section{Results and Discussion}

Table 1 shows the results of the previous study conducted by the authors (Sembiring, et al., 2006): 
Ferikawita M. Sembiring, Sulaeman Rahman, Nury Effendi and Rachmat Sudarsono

Table 1: The Abnormal Return of Portfolio in Period July 2005 - December 2015

\begin{tabular}{|c|c|c|c|c|c|}
\hline \multirow{2}{*}{ Description } & \multicolumn{2}{|c|}{$\begin{array}{c}\text { Abnormal Return } \\
\text { Loser }\end{array}$} & \multicolumn{2}{c|}{$\begin{array}{c}\text { Abnormal Return } \\
\text { Winner }\end{array}$} & \multirow{2}{*}{$\begin{array}{c}\text { Difference } \\
\text { Loser-Winner }\end{array}$} \\
\cline { 2 - 5 } & $\begin{array}{c}\text { Formation } \\
\text { Period }\end{array}$ & $\begin{array}{c}\text { Testing } \\
\text { Period }\end{array}$ & $\begin{array}{c}\text { Formation } \\
\text { Period }\end{array}$ & $\begin{array}{c}\text { Testing } \\
\text { Period }\end{array}$ & \\
\hline Mean & -0.120645 & 0.179905 & 0.070545 & -0.046955 & 0.225625 \\
\hline Maximum & -0.045400 & 0.479900 & 0.175400 & -0.008000 & 0.487900 \\
\hline Minimum & -0.296800 & 0.038300 & 0.023700 & -0.158700 & 0.081200 \\
\hline Standard Deviation & 0.069285 & 0.104159 & 0.042867 & 0.036564 & 0.096110 \\
\hline Observation & 20 & 20 & 20 & 20 & 20 \\
\hline
\end{tabular}

The current study will test conditional CAPM, or dual beta, determining whether the performance of the dual beta is able to outperform a single beta. The single beta will be tested first, followed by the dual beta. Table 2 shows the results of the cross section regression for the single beta.

Table 2: A Testing Result of Single Beta in Period January 2006-December 2015

\begin{tabular}{l|c|c|c|}
\hline \multicolumn{4}{|c|}{$\overline{\left(\mathrm{R}_{\mathrm{p}}-\mathrm{R}_{\mathrm{f}}\right)=\lambda_{0}+\lambda_{1} \beta_{\mathrm{i}}+\mathrm{e}_{\mathrm{i}}}$} \\
\hline Portfolio & $\lambda_{0}$ & $\lambda_{1}$ & F-stat \\
\hline Winner & $\left.0.0109^{* * *}\right)$ & 0.0078 & 3.6860 \\
\hline Loser & $\left.0.0312^{* * *}\right)$ & $\left.-0.0145^{* *}\right)$ & \\
\hline$* *)$ significant at $\alpha=1 \%$ & & \\
$* *)$ significant at $\alpha=5 \%$
\end{tabular}

Table 2 shows inconsistency in the results with the required conditions in testing the CAPM, where the slope of SML for winners is positive but not significant, while the slope of SML for the loser is significant but negative. The next step is to test the dual beta and compare the results with the results of the single beta testing. The use of a single beta will lead to a mutual off-set between slopes SML of an up market and a down market, so that the average beta will be close to zero. The implication is that the beta gives virtually no explanation for the returns of the portfolio.

Related with the dual beta model, investors who consider market timing will determine the structure of the portfolio with a high beta, if the market is estimated to have a higher return than the risk-free rate. On the other hand, investors will determine the structure of the portfolio with a low beta, if the market is expected to have a lower return than the risk-free rate. This strategy is based on the idea that, during the up market, a portfolio with a high beta would have expected returns larger than a portfolio with low beta, and vice versa.

However, if an investor does not make an accurate prediction of the direction of the market, then the expectation of the returns of the portfolios with a high beta (low) may be lower (higher) than the expected return of the portfolio with low beta (high). This will cause a loss or loss of potential gain for investors. If the movement of the market tends to go down, there will be a greater loss on the portfolio with a beta that is higher when compared with the portfolio with low beta.

In the process of testing a dual beta, of the 120 months observed, there were 76 periods of up market conditions and 44 periods of down market conditions. After testing the hypotheses, the following results were generated: 
Table 3: A Testing Result of the Winners and Losers Beta in Up Market and Down Market for Period January 2006 - December 2015

\begin{tabular}{|c|c|c|c|c|}
\hline \multirow[t]{2}{*}{ Description } & \multicolumn{2}{|c|}{$\begin{array}{c}\text { Up Market } \\
\left(\mathrm{R}_{\mathrm{p}}-\mathrm{R}_{\mathrm{f}}\right)_{\mathrm{i}}=\lambda_{0}+\lambda_{1} \beta_{\text {upi }}+\mathrm{e}_{\mathrm{i}}\end{array}$} & \multicolumn{2}{|c|}{$\begin{array}{c}\text { Down Market } \\
\left(\mathrm{R}_{\mathrm{p}}-\mathrm{R}_{\mathrm{f}}\right)_{\mathrm{i}}=\lambda_{0}+\lambda_{1} \beta_{\mathrm{dwi}}+\mathrm{e}_{\mathrm{i}}\end{array}$} \\
\hline & $\lambda_{0}$ & $\lambda_{1}$ & $\lambda_{0}$ & $\lambda_{1}$ \\
\hline $\begin{array}{l}\text { Winner } \\
\text { F-stat }\end{array}$ & $\left.0.0335^{* * *}\right)$ & $\begin{array}{l}0.0141 * *) \\
3.1200 * *)\end{array}$ & $\left.-0.0215^{* * *}\right)$ & $\begin{array}{r}-(0.0147 * *) \\
3.5599 * *)\end{array}$ \\
\hline $\begin{array}{l}\text { Loser } \\
\qquad \text { F-stat }\end{array}$ & $0.0493 * * *)$ & $\begin{array}{l}-0.0018 \\
0.1492\end{array}$ & $\left.-0.0155^{* * *}\right)$ & $\begin{array}{r}-0.0178 * *) \\
3.2751 * *)\end{array}$ \\
\hline
\end{tabular}

***) significant at $\alpha=1 \%$

**) significant at $\alpha=5 \%$

The results of the dual beta testing as shown in Table 3 demonstrate that in an up market, the slope of SML for winners is positive while in the down market, the slope is negative. These results are consistent with Pettengill, et al. (1995), and therefore confirm the hypotheses. However, the SML slope is found negative in the down-market conditions, but has no effect in the up market. These results therefore do not support the hypothesis that the SML slope in the up-market conditions are positive.

The use of a single beta provides virtually no explanation for the returns on a portfolio. However, as is seen in Table 3, the use of a dual beta can potentially generate an explanation for variations in returns more accurately.

The dual beta coefficient in winner portfolios shows that, when the market is segmented, beta can explain the portfolio returns in accordance with the required conditions in the CAPM model. While the single beta coefficient on the losers' portfolio shows a significant negative slope, when the market is segmented so that a dual beta is formed, the negative value becomes insignificant. These results are not in accordance with the condition that is required in the CAPM model but is supported by some empirical findings (De Bont and Thaler, 1987; Chopra, et al., 1992) which states that beta does not affect the return on a portfolio that is formed in conditions of market overreaction.

From all of the descriptions relating to testing the CAPM model, it can be concluded that the conditional CAPM model, or dual beta model, can be used to explain the variation of returns in a portfolio more efficiently than the standard CAPM model or a single beta model. These results are consistent with Pettengill, et al. (2002).

Furthermore, in completing the CAPM test results, the classical assumptions test is used to prove that the estimation model is accurate.

Table 4: A Testing Result of Classical Assumptions Conditional CAPM in Period January 2006-December 2015

\begin{tabular}{|c|c|c|c|c|}
\hline Portfolio & Market Timing & $\begin{array}{c}\text { Autocorrelation } \\
\text { (Durbin-Watson stat.) }\end{array}$ & $\begin{array}{c}\text { Heteroscedasticity } \\
\text { (White } \text { test } \text { ) }\end{array}$ & $\begin{array}{c}\text { Normality } \\
\text { (Jarque-Bera-JB test } \text { ) }\end{array}$ \\
\hline \multirow{2}{*}{ Winner } & Up market & 2.1662 & 2.0085 & 1.2170 \\
& Down Market & 2.3268 & 1.8000 & 0.5023 \\
\hline \multirow{2}{*}{ Loser } & Up market & 1.6265 & 1.7464 & 0.2425 \\
& Down Market & 1.8291 & 0.4245 & 1.5019 \\
\hline
\end{tabular}

Based on the test results as summarized in Table 4, it can be concluded that the estimation model is impartial because all assumptions of the BLUE (best linear unbiased estimator) have been met. These results also reinforce the conclusions derived from the results of the hypothesis testing, particularly in relation to the winners' portfolio (up market and down market) and for the losers (down market), which is consistent with the conditions required in the CAPM model. 
After estimating the slope of SML, the estimation process is carried out on the relationship between the dual beta and the returns portfolio to obtain the consistency of the test results as required in the CAPM model. Estimates of these relationships are shown in Table 5.

Table 5: A Testing Result of Dual Beta in Period January 2006 - December 2015

\begin{tabular}{|c|r|r|}
\hline \multirow{2}{*}{ Parameter } & \multicolumn{2}{|c|}{$\overline{R_{i}}=\alpha_{0}+\alpha_{1 .} \overline{\beta_{1 i}}+e_{i}$} \\
\cline { 2 - 3 } & \multicolumn{2}{|c|}{ Loser } \\
\hline$\alpha_{0}$ & $\left.-0.0550^{* *}\right)$ & -0.0170 \\
$\alpha_{1}$ & $\left.0.0954^{* * *}\right)$ & $\left.0.0458^{* * *}\right)$ \\
F-stat & $6.3848 * * *)$ & $\left.3.475663^{* *}\right)$ \\
\hline$* * *)$ significant at $\alpha=1 \%$ & & \\
$* *)$ significant at $\alpha=5 \%$ & & \\
\hline
\end{tabular}

The results in Table 5 show that dual beta has a positive and significant impact on portfolio returns of both winners and losers. These results are consistent with the conditions required in the CAPM model and they support the hypotheses of this study.

\section{Conclusion}

The purpose of this study is to test whether the model of conditional beta or dual beta model is able to explain the variation in portfolio returns more efficiently than the single beta model. The portfolio which is the object of this research is a portfolio of stocks that have been classified into winner and loser groups, based on their return reversal. This return reversal is an indicator of market overreaction conditions.

The test results indicate that portfolio returns can be explained better by the conditional beta model or a dual beta which separates the market into an up market and a down market. This is consistent with the findings of Pettengill et al. (1995). The results of a single beta test do not comply with the conditions required in the CAPM model and this can be corrected through conditional beta testing that includes the testing on the up beta, down beta, and the dual beta. Indeed, there are results from testing the conditional CAPM model that do not fit this theory, particularly in the loser portfolio, however the results are supported by several empirical studies related to conditions of market overreaction, such as the findings of De Bont and Thaler (1987).

This study has limitations related with the robust testing of CAPM model, as it only uses market factors as a determinant of returns. This study also fails to consider and explain the economic conditions that may affect returns. Further research may therefore attempt to test particular conditions referred to as the structural break analysis.

Further research may also add other factors which may affect returns, as proposed in multifactor models. By using statistic or econometric methods, we can test whether, if compared with the other factors, market factors are the most dominant factor influencing returns.

\section{References}

Bhardwaj, R. K., \& Brooks, L. D. (1993). Dual betas from bull and bear markets: reversal of the size effect. Journal of Financial Research, 16(4), 269-283.

Black, F., Jensen, M. C., \& Scholes, M. S. (1972). The Capital Asset Pricing Model: Some Empirical Test. Studies in The Theory of Capital Markets, New York: Praeger Publisher.

Charteris, A. (2014). Another look at the CAPM in South Africa: the influence of bull and bear markets. Journal of Economic and Financial Sciences, 7(2), 341-360.

Chopra, N., Lakonishok, J., \& Ritter, J. R. (1992). Measuring abnormal performance: do stocks overreact?. Journal of financial Economics, 31(2), 235-268. 
De Bondt, W. F., \& Thaler, R. H. (1987). Further evidence on investor overreaction and stock market seasonality. Journal of finance, 42, 557-581.

Fabozzi, F. J., \& Francis, J. C. (1977). Stability tests for alphas and betas over bull and bear market conditions. The Journal of Finance, 32(4), 1093-1099.

Fama, E. F., \& MacBeth, J. D. (1973). Risk, return, and equilibrium: Empirical tests. Journal of political economy, 81(3), $607-636$.

Fletcher, J. (2000). On the conditional relationship between beta and return in international stock returns. International Review of Financial Analysis, 9(3), 235-245.

Lintner, J. (1965). The Valuation of Risk Assets and The Selection of Risky Investments in Stock Portfolios and Capital Budgets. Review of Economics and Statistics, 47(1), 13-47.

Mossin, J. (1969). Equilibrium in Capital Asset Market. Econometrica, 34(4).

Pettengill, G. N., Sundaram, S., \& Mathur, I. (1995). The conditional relation between beta and returns. Journal of Financial and quantitative Analysis, 30(1), 101-116.

Pettengill, G., Sundaram, S., \& Mathur, I. (2002). Payment For Risk: Constant Beta Vs. Dual- Beta Models. Financial Review, 37(2), 123-135.

Reinganum, M. (1981). A New Empirical Perspective of the CAPM. Journal of Financial and Quantitative Analysis, 16, 439-460.

Sharpe, W. F. (1964). Capital asset prices: A theory of market equilibrium under conditions of risk. The journal of finance, 19(3), 425-442.

Sembiring, F. M., Rahman, S., Effendi, N., \& Sudarsono, R. (2016). Capital asset pricing model in market overreaction conditions: evidence from Indonesia Stock Exchange. Polish Journal of Management Studies, 14(2), 182-191. 